\title{
Peningkatan Kapasitas Masyarakat Dalam Mengurangi Risiko Bencana di Desa Bandung Rejo Kabupaten Gorontalo
}

\author{
Syahrizal Koem ${ }^{1}$, Noviar Akase ${ }^{2}$, Irwan Muis ${ }^{3}$ \\ 1,2,3 Jurusan Ilmu dan Teknologi Kebumian, FMIPA, Universitas Negeri Gorontalo \\ Email: s.koem@ung.ac.id'; noviar.akase@ung.ac.id²; irwanmuis97@ gmail.com³
}

\begin{abstract}
ABSTRAK
Program peningkatan kapasitas masyarakat dalam mengurangi risiko bencana bertujuan untuk mewujudkan desa Bandung Rejo sebagai desa tangguh bencana. Upaya yang dilakukan agar tercapainya peningkatan kapasitas masyarakat meliputi: (1) aspek kelembagaan melalui pembentukan forum Pengurangan Risiko Bencana (PRB) dan Tim Siaga Bencana Masyarakat (TSBM), (2) aspek pengembangan kapasitas melalui sosialisasi dan pelatihan penyusunan rencana pengurangan bencana dan rencana kontigensi, (3) aspek penyelenggaraan pengurangan bencana melalui program pembuatan peta ancaman serta pembuatan rambu-rambu peringatan dini bencana. Pembentukan forum PRB dan TSBM memiliki peran strategis dalam meminimalisir risiko bencana. Hasil yang dicapai dari sosialisasi dan pelatihan yaitu tersedianya dokumen analisis risiko bencana desa Bandung Rejo. Dokumen tersebut dapat menjadi rujukan dalam pengambilan kebijakan pembangunan di desa. Berdasakan hasil analisis yang dilakukan oleh forum bahwa desa Bandung Rejo memiliki tingkat bahaya banjir dengan kategori sedang. Hasil identifikasi dan analisis diperoleh dua titik rawan banjir yang mampu menjangkau lahan pertanian dan fasilitas sarana dan prasarana. Terselenggaranya program peningkatan kapasitas masyarakat di Desa Bandung Rejo dapat memberikan stimulus kepada pemerintah daerah dan masyarakat tentang pentingnya antisipasi bencana.
\end{abstract}

Kata Kunci: bencana alam, ketahanan, penilaian risiko

\section{ABSTRACT}

The community capacity building program in reducing disaster risk aims to realize the Bandung Rejo village as a disaster resilient village. Efforts made to achieve community capacity building include: (1) institutional aspects through the establishment of Disaster Risk Reduction forums (DRR) and Community Disaster Preparedness Teams (CDPT), (2) aspects of capacity building through dissemination and training in the preparation of disaster management plans and contingency plans, (3) aspects of the implementation of disaster management through a program to create a threat map and create disaster warning signs. The establishment of DRR and CDPT forums has a strategic role in minimizing disaster risk. The results achieved from the socialization and training were the availability of Bandung Rejo village disaster risk analysis document. The document can be a reference in making development policies in the village. Based on the results of the analysis conducted by the forum that Bandung Rejo village had a flood hazard level in the medium category. The results of identification and analysis obtained two flood-prone points that were able to reach agricultural land and facilities and infrastructure facilities. The implementation of community capacity building programs in Bandung Rejo village can provide stimulus to local governments and the public about the importance of disaster anticipation.

Kata Kunci: natural disasters, resilience, risk assessment 


\section{PENDAHULUAN}

Peristiwa bencana merupakan kejadian yang tak terduga, baik dari segi waktu, tempat, dan tingkat kerusakan yang di timbulkan. Dampak yang dirasakan oleh masyarakat akibat kejadian bencana diantaranya terganggunya tatanan kehidupan sosial, korban jiwa, gagal panen, dan kerugian ekonomi. Menurut Horrison dan Williams (2016) bahwa frekuensi dampak bencana dalam lingkup sosial dan ekonomi menunjukan peningkatan dalam beberapa dekade terakhir. Sebagai contoh, gempa dan tsunami yang terjadi di Aceh pada tahun 2004 menimbulkan korban jiwa dan hilangnya sumber pendapatan masyarakat (Ismail et al., 2018). Selain itu, bencana hidrometeorologi yang terjadi di Indonesia yang disebabkan cuaca ekstrim mengalami kenaikan (Adi, 2013). Kejadian cuaca ekstrim dapat berupa kondisi cuaca jauh dari normal. Sebagai contoh, cuaca ekstrim dapat menyebabkan terjadinya banjir dan kekeringan. Koem dan Rusiyah (2017) menyebutkan bahwa keragaman curah hujan di Kabupaten Gorontalo selama 35 tahun terakhir tidak lepas dari pengaruh fenomena El-Nino Southern Oscillation (ENSO), yang bengakibatkan banjir dan kekeringan dengan durasi dan intensitas yang beragam.

Kejadian cuaca ektrim juga terkait erat dengan perubahan iklim. Di sisi lain, Kabupaten Gorontalo merupakan wilayah yang mememiliki kerentanan tinggi dan kapasitas adaptif rendah terhadap perubahan iklim (DNPI, 2011). Rendahnya kapasitas adaptif terhadap bencana alam dapat menyebabkan kerugian pada berbagai sektor. BNPB (2015) menjelaskan bahwa kelompok masyarakat rentan dan kerugian ekonomi di Kabupaten Gorontalo yang diakibatkan oleh bencana berada pada kategori tinggi. Tingginya masyarakat rentan dan kerugian ekonomi yang ditimbulkan oleh bencana, mengindikasikan bahwa kurangnya kapasitas dalam meminimalisir risiko bencana. Hal tersebut perlu diantisipasi, khususnya di desa Bandung Rejo yang merupakan salah satu desa di Kabupaten Gorontalo digolongkan ke dalam kategori risiko banjir tinggi (ICCTF, 2017).

Hasil pengamatan di lapangan menunjukkan desa Bandung Rejo dilalui oleh sungai yang sewaktuwaktu dapat meluap, disisi lain sistem drainase di desa tersebut sebagian tidak berfungsi. Selain itu, partisipasi masyarakat dalam melakukan penanaman pohon masih kurang sehingga berpotensi terjadinya banjir. Disisi lain, di desa tersebut belum pernah diadakan pelatihan dalam upaya melakukan tindakan penaggulangan risiko bencana. Oleh karena itu, tujuan dilaksanakanya program peningkatan kapasitas masyarakat dalam mengurangi risiko bencana yaitu terwujudnya desa Bandung Rejo sebagai desa tangguh bencana. 


\section{METODE PENELITIAN}

Upaya yang dilakukan untuk mencapai hasil yang diharapkan dalam peningkatan kapasitas masyarakat desa Bandung Rejo dalam menanggulangi risiko bencana alam, mengacu pada beberapa aspek yang diwujudkan dalam program kegiatan. Aspek-aspek tersebut meliputi:

\section{Kelembagaan}

Berdasarkan hasil wawancara dengan kepala desa dan masyarakat desa Bandung Rejo, lembaga yang dibentuk khusus untuk penaggulangan bencana belum terealisasi, sehingga program ini merupakan yang paling mendasar untuk dilaksanakan. Indikator capaian pada aspek kelembagaan yaitu terbentukya forum Pengurangan Risiko Bencana (PRB) dan Tim Siaga Bencana Masyarakat (TSBM). Adapun sistem rekrutmen anggota forum melalui wawancara.

\section{Pengembangan kapasitas}

Program yang ditekankan pada aspek pengembangan kapasitas masyarakat desa Bandung Rejo, diantaranya sosialisasi dan pelatihan kepada forum PRB dan TSBM tentang teknik menyusun rencana pengurangan risiko bencana dan rencana kontigensi berdasarkan rekam peristiwa bencana yang pernah terjadi sebelumnya. Selain itu, melibatkan warga desa Bandung Rejo dalam melakukan langkah-langkah adaptasi dan mitigasi bencana seperti penanaman pohon dan panataan lingkungan.

\section{Penyelenggaraan pengurangan risiko bencana}

Menilai tercapainya aspek peyelenggaraan pengurangan risiko bencana di desa Bandung Rejo yaitu melalui pelaksanaan program pembuatan peta tingkat bahaya bencana di desa. Program ini dilakukan dengan cara mengidentifikasi titik kejadian bencana yang menimpa desa Bandung Rejo dalam kurun waktu 20 tahun terkahir, selanjutnya dilakukan survei lapangan untuk pengambilan titik koordinat pada daerah rawan bencana. Selain itu, dilakukan pembuatan peta jalur evakuasi dan sistem pringantan dini bencana.

\section{HASIL DAN PEMBAHASAN}

\section{Forum pengurangan risiko bencana (PRB) dan tim siaga bencana masyarakat (TSBM)}

Pembentukan forum PRB dan

TSBM di desa Bandung Rejo diawali dengan musyawarah bersama aparat desa, kepala dusun, karang taruna, dan masyarakat setempat. Keterlibatan masyarakat dalam melakukan langkah-langkah adaptasi dan mitigasi bencana menjadi prioritas utama untuk dilibatkan dalam forum PRB dan TSBM. Selain itu, pemahaman masyarakat tentang akibat yang ditimbulkan oleh bencana alam sangat penting. Hasil survei pemahaman tentang akibat yang ditimbulkan oleh bencana alam (banjir) diperoleh bahwa $37,5 \%$ masyarakat memilih kerusakan lahan dan tanaman (Gambar 1), sedangkan 


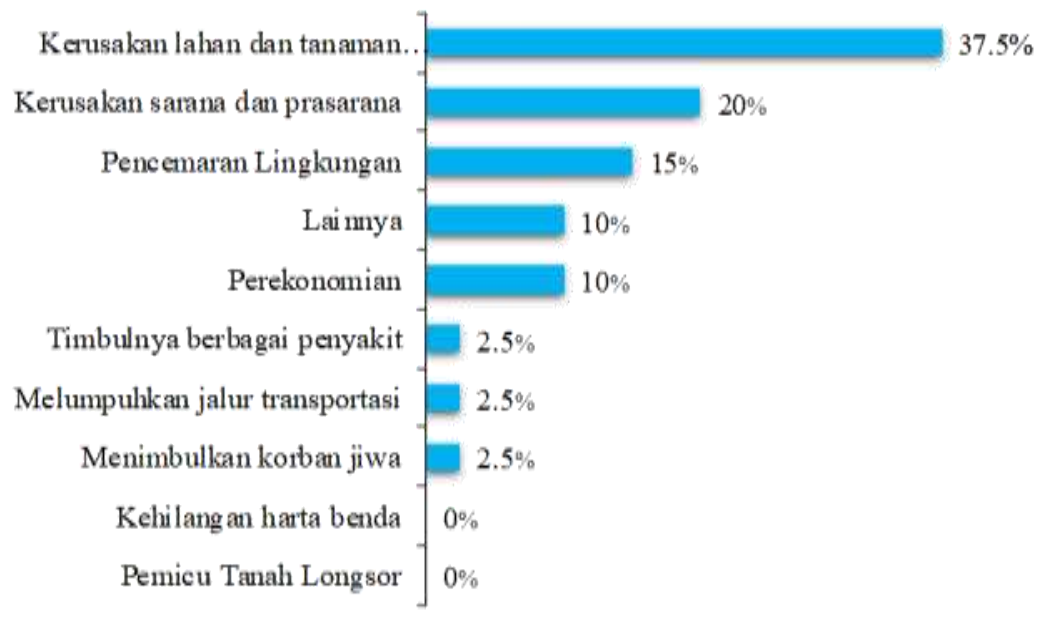

Gambar 1. Persentase responden akibat yang ditimbulkan oleh banjir

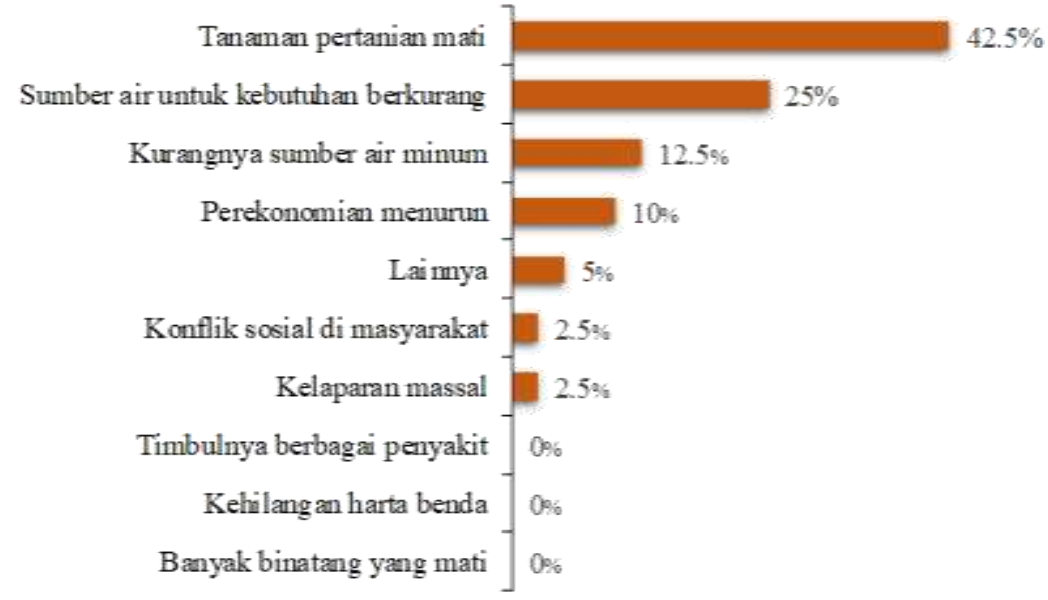

Gambar 2. Persentase responden akibat yang ditimbulkan oleh kekeringan

pemahaman tentang akibat yang ditimbulkan oleh bencana alam (kekeringan) diperoleh bahwa 42,5\% masyarakat memilih tanaman pertanian mati (Gambar 2).

Masyarakat yang memenuhi persyaratan dipilih dan menyatakan kesediannya untuk menjadi anggota forum PRB dan TSBM (Gambar 3a). Pembentukan forum PRB dan TSBM mendapat respon positif dari kepala desa dan masyarakat desa Bandung Rejo, karena memiliki peran strategis dalam meminimalisir risiko bencana alam dan sebagai unsur penentu dalam pengambilan kebijakan pembangunan di desa Bandung Rejo. Forum PRB dan TSBM yang telah dibentuk selanjutnya disahkan oleh kepala desa melalui surat keputusan (SK).

\section{Rencana pengurangan risiko bencana dan rencana kontigensi}

Forum PRB dan TSBM yang telah dibentuk dan disahkan oleh kepala desa Bandung Rejo, selanjutnya dibekali dengan materi tentang jenis-jenis bencana alam, penyebab bencana alam, dan cara menanggulangi serta mengantisipasi bencana alam. Kegiatan ini dilakukan melalui sosialisasi yang melibatkan 
instruktur yang berasal dari Badan Penanggulangan Bencana Daerah (BPBD). Sosialisasi juga dilaksanakan dengan materi dasar hukum pembentukan forum PRB dan TSBM serta pemahaman mengenai karakteristik wilayah.

Forum PRB dan TSBM dilatih untuk mengenali karakteristik wilayah misalnya mengetahui topografi wilayahnya, jalan yang bebas hambatan, sebaran masyarakat yang rentan (bayi, balita, usia lanjut dan berkebutuhan khusus), titik rawan bencana dan titik kumpul atau titik aman evakuasi (Gambar 3b). Pengenalan karakteristik wilayah berfungsi agar ketika terjadi bencana, forum PRB dan TSBM dapat melakukan evakuasi tanggap darurat dengan mudah, karena mereka telah memahami dan mengetahui karakteristik wilayah dan apa yang
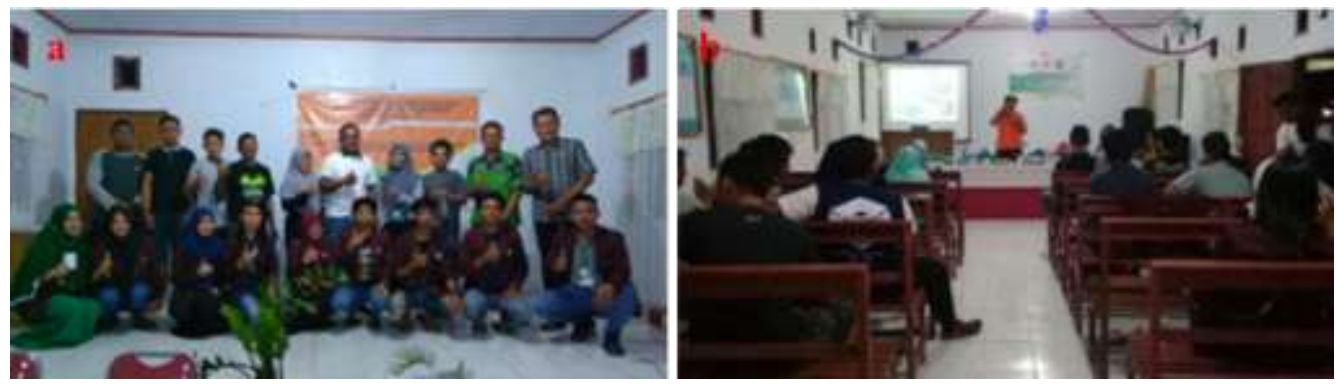

Gambar 3. a) Pembentukan forum PRB dan TSBM, b) sosialisasi dan pelatihan rencana pengurangan risiko bencana dan rencana kontigensi
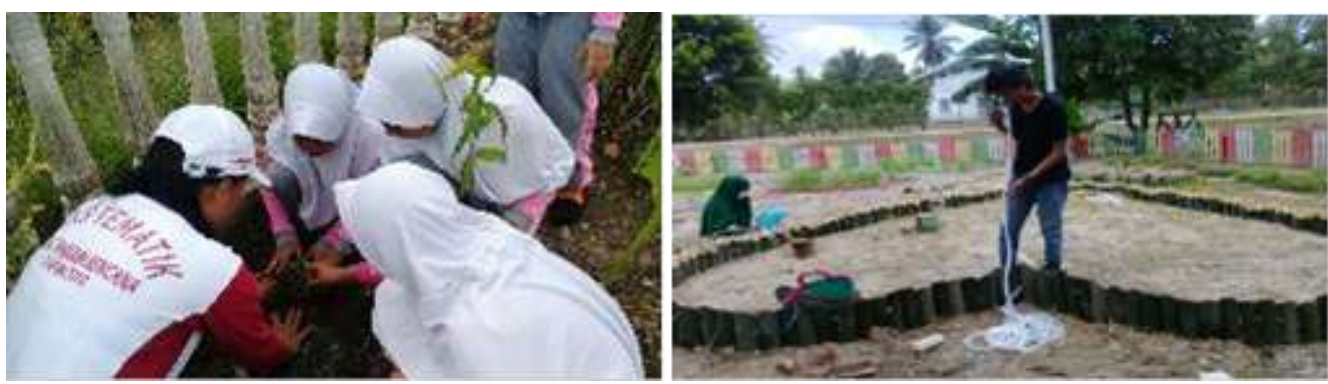

Gambar 4. Pelibatan warga desa Bandung Rejo pada penanaman pohon disekitar area rawan bencana dan penataan taman harus dilakukan ketika terjadi tanggap darurat. Selain itu, forum PRB dan TSBM dilatih untuk mengidentifikasi dan menentukan bencana yang sering terjadi di desa, menentukan wilayah yang terkena dampak bencana, selanjutnya menentukan tingkat kerentanan, kapasitas dan risiko bencana.

Hasil yang dicapai dari pelatihan ini adalah masyarakat mampu menganalisis tingkat risiko bencana yang terjadi di desa Bandung Rejo serta sebaran dampak bencana kemudian dituangkan dalam dokumen tangguh bencana. Dokumen tersebut menjadi rujukan dalam pengambilan kebijakan pembangunan di desa. Selain itu, masyarakat dilibatkan dalam penataan lingkungan dan penanaman pohon di area rawan banjir. 


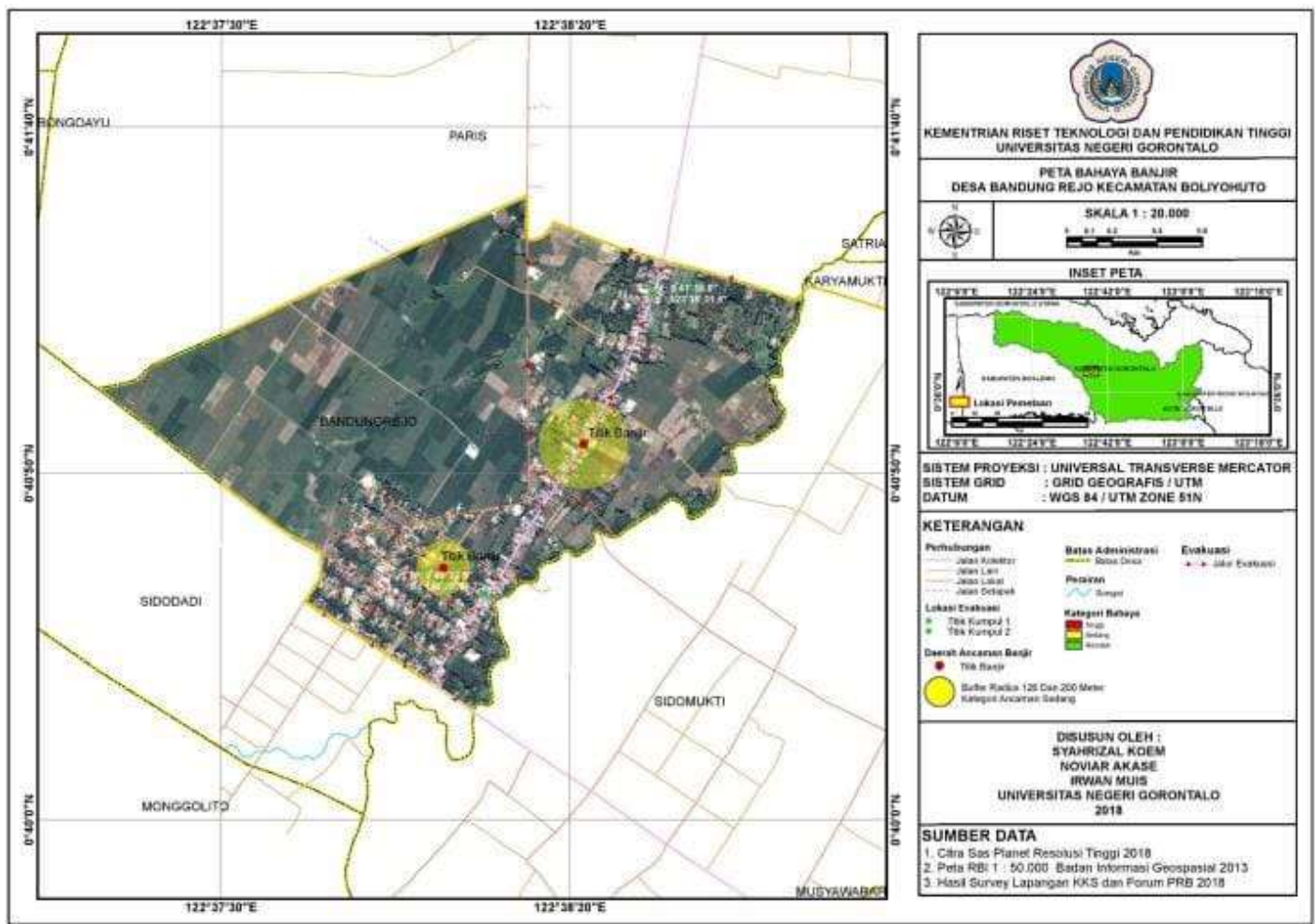

Gambar 5. Peta bahaya banjir dan jalur evakuasi desa Bandung Rejo

Kegiatan ini merupakan cara masyarakat untuk melakukan langkah-langkah adaptasi dan mitigasi bencana alam (Gambar 4). Selain itu, melalui pelatihan yang dilaksanakan, forum PRB dan TSBM dilatih untuk melakukan analisis terhadap indeks ketangguhan desa Bandung Rejo berdasarkan indikator yang ditetapkan oleh BPBD. Kesimpulan hasil analisis ketangguhan desa yang diperoleh bahwa desa Bandung Rejo digolongkan sebagai desa belum tangguh terhadap bencana.

\section{Membuat peta analisis bahaya bencana}

Setelah forum PRB dan TSBM dibekali dengan materi kebancanaan pada sosialisasi dan teknik analisis kebencanaan melalui pelatihan.
Selanjutnya forum di arahkan untuk dapat membuat peta dan analisis ancaman. Proses pembuatan peta oleh forum, didampingi oleh dosen dan mahasiswa pelaksana pengabdian agar menghasilkan peta sesuai standar yang diharapkan.

Pengumpulan data di lapangan untuk pembuatan peta berupa data jumlah lansia, ibu hamil, dan balita kemudian diklasifikasikan sebagai penduduk yang rentan terhadap bencana. Pembuatan peta dan analisis ancaman bertujuan mengidentifikasi wilayah yang dianggap memiliki risiko tinggi jika terjadi bencana. Selain itu, mengidentifikasi masalahmasalah yang dihadapi oleh wilayah yang rawan untuk melakukan rencana pengelolaan bencana, serta membantu evakuator dalam pengambilan 


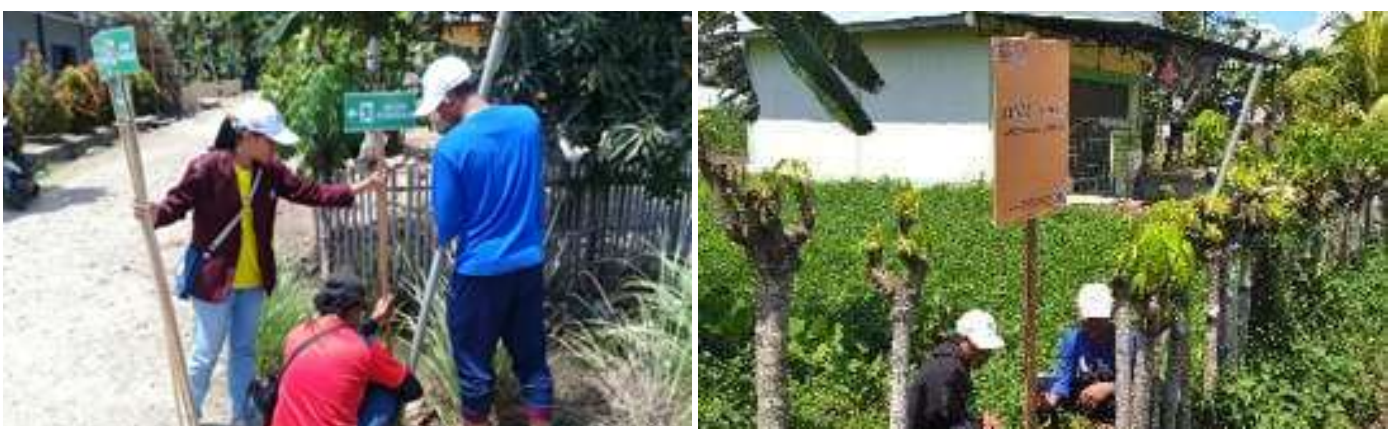

Gambar 6. Pemasangan rambu-rambu peringatan dini bencana

keputusan dalam bertindak sebelum dan sesudah terjadinya bencana.

Hasil yang diperoleh melalui program ini, berupa peta bahaya banjir, penentuan jalur evakuasi, dan titik kumpul. Berdasakan hasil analisis yang dilakukan oleh forum bahwa desa Bandung Rejo memiliki tingkat bahaya banjir dalam kategori sedang. Selain itu, hasil identifikasi dan analisis desa Bandung Rejo terdapat dua titik rawan banjir yang mampu menjangkau lahan pertanian yaitu sawah dan fasilitas sarana dan prasarana yaitu sekolah (Gambar 5).

\section{Membuat rambu peringatan dini bencana}

Metode yang digunakan dalam membuat rambu-rambu peringatan dini bencana di desa Bandung Rejo yaitu metode observasi. Pemasangan rambu-rambu peringatan dini bencana dilakukan disetiap titik yang teridentifikasi rawan bencana, dalam hal ini titik rawan banjir. Lokasi titik kumpul dibuat dua titik, penentuan titik kumpul mempertimbangkan jumlah daya tampung dan jangkauan masyarakat menuju lokasi tersebut (Gambar 6). Selain itu pemasangan jalur evakuasi dilakukan dengan mempertimbangkan minimnya faktor-faktor yang dapat menghambat proses evakuasi saat terjadi bencana dan kelancaran masyarakat menuju titik kumpul.

Manfaat yang diperoleh ketika rambu-rambu peringatan dini bencana dipasang yaitu masyarakat semakin menyadari bahwa pentingnya mengamati lingkungan sekitar yang bisa menimbulkan risiko yang besar saat terjadi bencana seperti banjir dan gempa bumi. Selain itu, menumbuhkan solidaritas baik masyarakat maupun pemerintah dalam menyiapkan diri saat sebelum dan setelah terjadinya bencana.

Terlaksananya

program tersebut, diharapkan dapat mempermudah masyarakat untuk melakukan tindakan evakuasi secara cepat dan tepat tanpa menyebabkan korban jiwa. Selain itu, dapat meningkatkan kemampuan masyarakat dalam melakukan upaya penyelamatan pada jenis bencana lainnya.

\section{Tindaklanjut program}

Program-program yang telah dilaksanakan merupakan langkah awal bagi masyarakat dalam upaya 
meningkatkan kapasitas pengurangan risiko bencana. Selain itu, memudahkan instansi terkait dalam hal ini pemerintah Kabupaten Gorontalo melalui BBPD untuk memeberikan pelatihan lanjutan kepada forum PRB dan TSBM. Salah satu prioritas dalam peningkatan kapasitas yaitu penyusunan dokumen dianjurkan memuat teknik mitigasi bencana yang disebabkan oleh iklim ekstrim serta disusun berdasarkan kondisi eksisting di desa tersebut. Pengaruh perubahan iklim, pengunaan lahan dan perubahan sosial yang terus terjadi, sehingga mempengaruhi kapasitas penaggulangan bencana dimasa depan. Oleh karena, itu updating peta dan analisis risiko bencana perlu dilakukan penyesuaian berdasarkan perubahan kondisi tersebut.

\section{SIMPULAN}

Terselenggaranya program peningkatan kapasitas masyarakat di desa Bandung Rejo dapat memberikan stimulus kepada pemerintah daerah dan masyarakat tentang pentingnya antisipasi bencana. Selain itu, memberikan kesadaran tentang pentingnya menjaga dan memahami masalahmasalah fisik di lingkungan agar terhidar dari dampak yang merugikan. Pemahaman tentang bencana dan cara mengatasinya dapat dilakukan melalui intervensi perintah, sehingga dapat dituangkan dalam poin-poin kebijakan pemerintah daerah dan desa. Selain itu, tersedianya dokumen tangguh bencana yang telah disusun dapat dijadikan sebagai dasar pengambilan keputusan dalam merencanakan pembangunan di Desa Bandung Rejo.

\section{UCAPAN TERIMA KASIH}

Terima kasih kami ucapkan kepada LP2M Universitas Negeri Gorontalo atas dukungan dana yang bersumber dari PNBP tahun anggaran 2018. Terima kasih juga kami sampaikan kepada pemerintah Kabupaten Gorontalo dan BPBD Provinsi Gorontalo atas kerjasamanya melalui program Kuliah Kerja Sibermas (KKS) Tematik Desa Tangguh Bencana (DESTANA). Penghargaan kami berikan kepada kepala desa dan masyarakat desa Bandung Rejo atas kesediaanya menjadi mitra, sehingga program ini terlaksana dengan baik.

\section{DAFTAR PUSTAKA}

Adi, Seno. 2013. Karakterisasi bencana banjir bandang di Indonesia. Jurnal Sains dan Teknologi Indonesia. 15: 42-51.

[BNPB] Badan Nasional Penanggulangan Bencana. 2015. Kajian risiko bencana gorontalo 2016-2020. Gorontalo: Deputi bidang pencegahan dan kesiapsiagaan, pp. 8-20.

[DNPI] Dewan Nasional Perubahan Iklim. 2011. Pemetaan kerentanan di daerah provinsi serta inventarisasi kebijakan dan kelembagaan dalam rangka antisipasi dampak perubahan iklim. Jakarta: Kementerian BUMN, pp. 1-38.

Horrison, C.G., Williams, P.R. 2016. 
Syahrizal Koem ${ }^{1}$, Noviar Akase², Irwan Muis ${ }^{3}$ /Aksiologiya: Jurnal Pengabdian Kepada Masyarakat. Vol.3, No.2, Agustus 2019 Hal 176 - 184

A systems approach to natural disaster resilience. Simulation Modelling Practice and Theory. 65: 11-31.

[ICCTF] Indonesia Climate Change Trust Fund. 2017. Memperkuat Kelembagaan pemerintah daerah untuk mengintegrasikan adaptasi perubahan iklim dalam rencana pembangunan daerah. workshop \& ekspose laporan tahunan program hibah ICCTF-USAID Tahun 2016-2018. Bekasi, 28 April 2017.
Ismail, N., Okazaki, K., Ochiai, C., Fernandez, G. 2018. Livelihood changes in Banda Aceh, Indonesia after the 2004 Indian Ocean Tsunami. International Journal of Disaster Risk Reduction. 28: 439-449.

Koem, S., Rusiyah. 2017. Monitoring of drought events in Gorontalo regency. IOP Conf. Series: Earth and Environmental Science, 98, 012053. 